\title{
El consumo de información política de los públicos interesados comparado con el del electorado general. Los casos de las elecciones de Argentina, España y Venezuela de 2015
}

\section{Comparison between the political information consumption of the general voter and specialized audiences. The cases of the Argentinian, Spanish and Venezuelan 2015 elections}

Carmen Beatriz Fernández y Jordi Rodríguez-Virgili'

Recibido: 23-05-2017 - Aceptado: 14-07-2017

DOI: https://doi.org/10.26441/RC16.2-2017-A3

RESUMEN: El patrón de consumo de información política varía de acuerdo a los distintos públicos, no sólo en su intensidad de uso, sino también en los diversos medios de comunicación utilizados para informarse. Este artículo compara los patrones de información política de los públicos más interesados (periodistas, académicos, consultores y dirigentes políticos) con la manera de informarse políticamente de los electores en general, tomando como caso de estudio las elecciones argentinas, españolas y venezolanas del año 2015.

Palabras clave: infopolítica; uso de medios; elecciones críticas; comunicación política; Argentina; España; Venezuela.

ABSTRACT: Different publics consume political information in different ways. The pattern of consumption of political information varies according to the different publics, not only in their intensity of use, but also in the various communication outlets used to inform themselves. This article compares the patterns of political information for the most interested publics (journalists, academics, consultants and political leaders) with general voters, taking as a case the study of the Argentinian, Spaniard and Venezuelan elections of 2015.

Keywords: infopolitics; media use; critical elections; political communication; Argentina; Spain; Venezuela.

1 Carmen Beatriz Fernández es Magíster en Administración de Empresas (IESA, Venezuela) y en Campañas Electorales (University of Florida, USA). Es profesora del IESA en Comunicación Política y Urbanista (USB, Venezuela). Actualmente es aspirante doctoral de la Universidad de Navarra e investigadora invitada en su Center for Internet Studies and Digital Life. cbfer@datastrategia.com, http://orcid.org/0000-0003-0609-0695

Jordi Rodríguez Virgili es Licenciado en Periodismo, Doctor en Ciencias de la Información por la Universidad de Navarra y Profesor titular de Comunicación Política de la misma universidad. Actualmente es Vicedecano de Profesorado y Ordenación Académica de su Facultad de Comunicación e Investigador del Center for Internet Studies and Digital Life de la Universidad de Navarra. jrvirgili@unav.es, http://orcid.org/0000-0002-7952-5664 


\section{Introducción}

Este trabajo pretende mostrar cómo se informan sobre política los agentes más interesados e implicados en ella y contrastarlo con la manera de informarse políticamente del electorado en general. Se tomaron cuatro tipos de públicos como representantes de los actores más interesados e implicados en política, que fueron los dirigentes y cargos políticos, consultores políticos, periodistas políticos, y por último, académicos relacionados con la enseñanza e investigación de la política, como podían ser profesores de Ciencias Políticas, Comunicación Política, Derecho político o Derecho Constitucional. Este trabajo forma parte de un estudio comparado más amplio sobre el uso de Internet en política, la denominada "ciberpolítica”, en tres elecciones críticas celebradas en 2015: las de Argentina, España y Venezuela.

A su vez, ese estudio cuenta con el antecedente de una investigación sobre la ciberpolítica en América Latina realizado en 2006, donde se distinguieron dos usos principales de la red: como herramienta de comunicación política, que se denominó de forma genérica "infopolítica", y como herramienta de organización y movilización política, entendida bajo el concepto de "ciberactivismo" (Fernández, 2008: 23). En un artículo anterior de esta misma investigación sobre el concepto de "Infopolítica" se expuso cómo se infor- man sobre política los agentes más interesados (Rodríguez-Virgili y Fernández, 2017). El estudio identificó al entorno digital como el ámbito principal para informarse políticamente para los públicos más activos e interesados.

Christopher Arterton ya había abordado de forma pionera el tema de la ciberpolítica en un temprano estudio de 1987 titulado Teledemocracy (Arterton, 1987). Arterton se planteaba, a través una investigación empírica, si las nuevas tecnologías serían capaces de ofrecer una nueva democracia, más parecida al ideal griego, en la que la gran mayoría de los ciudadanos participaran activamente. En su libro proponía la hipótesis de la relación directa entre tecnología y participación, pero sus resultados experimentales no eran demasiado prometedores. Desde entonces, se han realizado un buen número de estudios acerca de cómo está produciéndose el paso desde la comunicación política tradicional a la comunicación política digital o ciberpolítica, así como sus implicaciones que en los procesos electorales, con especial atención al fomento de la participación ciudadana y la movilización social (Mazzoleni, 2001; Holtz-Bacha, 2013; Maarek, 2014).

El uso del Internet en la región iberoamericana alcanza ya a un mayoritario $52 \%$ del total de la población ${ }^{2}$, dato muy distinto a cuando se hizo el primer estudio de 2006, cuando las tasas

2 www.internetworldstats.com 
promedio eran del 17\% (Fernández, 2008). Con todo, aún existen importantes variaciones y altibajos en los distintos países que integran la subregión. Es evidente que este importante aumento en la penetración del Internet sugiere también un aumento equivalente en el uso de los medios digitales para informarse y movilizar políticamente

Este artículo se limita a presentar un análisis con fundamento empírico de los principales hallazgos de la dimensión Infopolítica en un momento determinado, la campaña electoral, y contrastarla en un segmento concreto, el público más implicado e interesado en política, con el de los electores normales. Es decir, cuáles son los canales habituales de información política de los actores vinculados de forma más directa con la política, como son los cargos políticos, los periodistas, los académicos o profesores y los consultores políticos, durante la fase más intensa de consumo informativo, las elecciones. Para, a continuación, compararlos con el de los ciudadanos e identificar así posibles similitudes y diferencias, partiendo de la hipótesis de que podrían existir diferencias importantes entre ambos tipos de audiencias.

Para abordar este análisis, se explicará en primer lugar qué se entiende por Infopolítica, a continuación se recordará el concepto de elecciones críticas y se justificará la pertinencia los casos seleccionados, los comicios de Argentina, España y Venezuela en 2015, se detallará brevemente la metodología empleada, para proceder al análisis y discusión de los resultados, y, por último, apuntar algunas ideas a modo de conclusión.

\section{Infopolítica o consumo de informa- ción política}

El término consumo mediático se refiere al uso y los hábitos asociados a los diferentes medios de comunicación y que, dado el proceso de convergencia mediática, en la actualidad son en gran medida subsumidos por Internet, donde son accesibles contenidos de medios como los periódicos, las revistas, la radio o la televisión; además de los elementos propiamente digitales (SerranoPuché, 2017). En consecuencia, se entiende por Infopolítica al consumo mediático sobre la información política.

La consolidación de los medios de comunicación como espacio primordial de debate público ha afianzado un modelo de política mediatizada, por el cual los medios se erigen en los agentes de intermediación por excelencia entre las élites políticas y los ciudadanos (Castells, 2009; Mazzoleni, 2010, Rodríguez-Virgili et al, 2011). Este poder mediático se vuelve especialmente central en el contexto de las campañas electorales. Sin embargo, las características del espacio público están evolucionando rápidamente en los últimos años con la irrupción de Internet, lo que ha provocado una acelerada reconfiguración del ecosistema comunicativo.

El impacto de Internet en la comunicación política ha suscitado un intenso debate académico (Arterton, 1987; Jenkins \& Thorburn, 2003; Dahlgren, 2005; Del Rey Morato, 2007; Hendricks \& Kaid, 2010; 
Giansante, 2015). Los medios digitales reducen las limitaciones de tiempo y espacio y la información política se convierte en un flujo continuo, que incluso trastoca un componente esencial de las profesiones informativas, que han pasado de la periodicidad temporal como base de su tarea a tener que enfrentarse a la realización de "un periodismo sin períodos" (Martín Algarra, Torregrosa y Serrano-Puche, 2013). Además, los medios de comunicación han perdido el cuasi monopolio que tenían sobre la información política, que ya no sólo ofertan los medios tradicionales, sino también distintos agentes como políticos, ciudadanos, activistas, laboratorios de ideas o asociaciones cívicas a través de las múltiples plataformas comunicativas (Bowman y Willis, 2003; Kelly, 2008). En la actualidad, todos los usuarios están sometidos en mayor o menor medida a diferentes flujos informativos (Díaz Arias, 2015).

En consecuencia, el poder de los medios experimenta un continuo proceso de flexibilización, si bien éstos todavía mantienen una fuerte centralidad en la comunicación política, en tanto que la información desplegada por los medios sigue marcando el tono y la agenda de la discusión pública (Castells, 2009). Sin embargo, la proliferación y el rápido desarrollo tecnológico de los medios contemporáneos no significan necesariamente que haya un aumento de la información política o que se consuma más. Porque ese conjunto de información política que es adquirido por el usuario no sólo depende de su disponi- bilidad, también está condicionado por factores como el hábito, el interés y la competencia, correlacionados con características sociodemográficas como la edad, la educación, la nacionalidad, nivel de ingresos o la ocupación profesional (Meilán, 2010).

En definitiva, el espacio público se constituye a partir de un incipiente sistema híbrido de medios de comunicación (Chadwick, 2013), del que participan -y se interrelacionan constantemente- tanto los medios analógicos como los medios digitales y en el que las variables relacionadas con las preferencias personales, necesidades y expectativas son relevantes para explicar el consumo de información. Precisamente, la incidencia de uno de estos factores, el interés o implicación por la política, en el consumo de información política es la variable principal que se analiza en este estudio.

Con la información política disponible y la diversidad de medios que la proveen (prensa, radio, televisión, webs, redes sociales, medios digitales...), los individuos seleccionan tanto los medios como los contenidos. ¿Y cómo eligen las personas la información política que tienen a su disposición? Iyengar y McGrady (2007) sugieren tres posibilidades. A través de la «polarización sesgada», las personas prefieren encontrarse con información que les permita reafirmar sus creencias, evitando aquella que les genere inconsistencias. Otra opción es que las personas, al buscar información sobre "asuntos públicos" que les interesan, no utilizan información respecto a otros hechos. Por último, 
aquellas personas que tienen interés en política sintonizan con toda la información disponible.

En suma, en el amplio análisis de la literatura académica realizado sobre esta materia, se pretende aportar un estudio original que ayude a comprender cómo se configura la adquisición de información política por parte de unos públicos interesados y activos políticamente en campañas de elecciones críticas, explorar las diferencias entre estos públicos y la población de electores en general, así como apuntar algunas con- secuencias que de ello se derivan.

\section{Elecciones críticas: Argentina, España, Venezuela 2015}

Argentina, España y Venezuela, tres de las sociedades más ciberconectadas de Hispanoamérica, celebraron elecciones en el año 2015. Los tres países tienen niveles de penetración a Internet que están por encima de la media regional, oscilando entre el $60 \%$ de la población en Venezuela y el $75 \%$ para los casos de Argentina y España, según datos 2014 del World Internet Stats (Cuadro 1):

Cuadro 1. Datos comparados de penetración de Internet y uso de Facebook

\begin{tabular}{|l|c|c|c|c|}
\hline \multicolumn{1}{|c|}{ País } & Población & $\begin{array}{c}\text { Usuarios } \\
\text { Internet }\end{array}$ & Penetración \% & Usuarios Facebook \\
\hline Argentina & 43.024 .374 & $32,268,280$ & $75.0 \%$ & $20.594 .680,(47.9 \%)$ \\
\hline España & 47.737 .941 & $35,705,960$ & $74.8 \%$ & $17.590 .500,(36.8 \%)$ \\
\hline Venezuela & 28.868 .486 & $15,960,691$ & $60,3 \%$ & $9.808 .560,(34.0 \%)$ \\
\hline
\end{tabular}

Fuente: World Internet Stats, 2014

Con estos datos aumenta el interés por el análisis comparativo de la ciberpolítica en sus campañas electorales en comicios ya de por sí relevantes y diferentes. La de Argentina constituyó una elección presidencial, mientras que las de España y Venezuela fueron legislativas, la primera en un sistema parlamentario que debía originar la formación de un Gobierno, y la segunda en un sistema presidencialista. Sin embargo, las tres contiendas pueden identificarse como "elecciones críticas" en el sentido que le atribuyó V.O. Key (1955), como aquellas en que la intensidad de la participación es alta e implica un re- alineamiento duradero en la estructura político-partidista de una sociedad.

El académico norteamericano de la Universidad de Harvard introdujo en el artículo $A$ theory of critical elections, publicado en The Journal of Politics, un concepto que sería relevante para la taxonomía electoral de las siguientes décadas. Key definió las elecciones críticas como:

Una categoría de elecciones en la que los votantes están inusualmente preocupados, en la que la medida de compromisos y vinculación con la campaña es relativamente alta, y en la que los resultados de la elección revelan una alteración aguda de los segmentos 
pre-existentes dentro del electorado (Key, 1955: 4).

Key analizaba en su estudio las estadísticas electorales de casos en los que se habían experimentado cambios importantes en la conducta política y en el voto de ciertos segmentos relevantes de la población, empleando variables como rural-urbano, religión o niveles de ingresos como criterios principales. No analizaba el país entero, su trabajo empírico se ceñía a unas determinadas elecciones, circunscritas a espacios geográficos particulares.

Key puso particular énfasis en la duración relativa del fenómeno electoral, porque aunque se manifiesta en las elecciones observadas parece subsistir en elecciones posteriores. Es decir, la elección crítica sería, según Key: "una elección en la cual la profundidad y la intensidad del compromiso electoral es alto, hay reajustes más o menos profundos en las relaciones de poder dentro de la comunidad, y se forman nuevos y duraderos agrupamientos electorales" (Key, 1955: 5). Pese a que Key se refirió en su estudio al caso particular de New England en la costa noreste de los Estados Unidos, en las elecciones de 1928 y 1932, su concepto es generalizable y extensible como definición de un fenómeno de conducta política mucho más amplio. Las tres elecciones objeto de estudio seleccionadas parecen cumplir con los requisitos del concepto acuñado por Key, por lo que hace especialmente interesante su análisis comparado.

El triunfo de Mauricio Macri en las elecciones presidenciales argentinas de noviembre de 2015 marcó el fin de la era kirchnerista. La alta intensidad del compromiso electoral en esos comicios se comprueba en la participación del $81 \%$ del censo en la segunda vuelta. El reajuste profundo en las relaciones de poder y los nuevos agrupamientos electorales se produce, por una parte, en el fin del kirchnerismo, que había llegado al poder en 2003 con Néstor Kirchner y que, tras su fallecimiento, fue sucedido electoralmente por su esposa Cristina Fernández. Y por otra, quizá más importante pensando en sus implicaciones en relación a los realineamientos políticos de la sociedad, por la definitiva emergencia de un partido joven, el PRO, que gana el poder nacional. Desde la dictadura militar que terminó en 1983, sólo dos partidos políticos, y sus alianzas coyunturales, habían alcanzado el poder nacional: la Unión Cívica Radical y el Partido Justicialista. Es decir, era la primera vez en un siglo que alguien que no era peronista ni radical alcanzaba la presidencia de la República Argentina.

Las elecciones generales celebradas en España el 20 de diciembre de 2015 contaron con una participación del $73,2 \%$ del electorado, casi cinco puntos por encima de los anteriores comicios. $\mathrm{Y}$, sin duda, revelan una alteración de los segmentos pre-existentes dentro del electorado porque, por primera vez en la historia de la democracia española, cuatro partidos superaban el $10 \%$ de los votos y se cuestionaba el bipartidismo imperfecto dominado por las dos grandes fuerzas políticas, el Partido Popular (PP) y el Partido Socialista Obrero 
Español (PSOE). En efecto, el realineamiento de las preferencias político-partidistas del electorado español fue evidente: el PP mantuvo la mayoría pero con tan solo el $28,7 \%$ de los votos, el PSOE cayó al 22\% y los partidos emergentes obtuvieron más del $17 \%$ de los votos en el caso de Podemos y sus confluencias, y el $14 \%$ en el de Ciudadanos. El resultados de los comicios de 2016, repetición electoral ante la incapacidad de los partidos de formar Gobierno, ratifica esta alteración de las preferencias político-partidistas de los españoles.

Finalmente, las elecciones parlamentarias del 6 de diciembre 2015 en Venezuela también pueden calificarse de críticas por el cambio en las preferencias políticas de los votantes. Con una participación del 74,17\% del electorado, un incremento del $7,7 \%$ respecto a las legislativas de 2010, las elecciones a la Asamblea Nacional dieron a la oposición venezolana una importante victoria. $\mathrm{La}$ Mesa de la Unidad Democrática (MUD), principal movimiento de oposición al presidente Nicolás Maduro, alcanzó 112 diputados de los 167 que componen la Asamblea Nacional. Con el 56,2\% de la votación nacional la oposición se hizo con el $72 \%$ de la representación parlamentaria y cerró el largo ciclo de victorias electorales del chavismo que había durado 17 años y más de una docena de elecciones.

\section{Metodología}

La investigación se enmarca dentro de los estudios basados en encuestas, es decir, se intenta conocer las respuestas y examinar las hipótesis en condiciones no controladas por los investigadores. En este estudio se cruzan los datos de distintas encuestas a distintos públicos, lo que sin duda, limita las conclusiones del estudio e impide afirmaciones definitivas, pero señalan tendencias, pistas, posibles pautas de indudable valor académico y profesional.

Para los públicos especialmente interesados en política, se empleó un cuestionario online. Se trató de un muestreo no probabilístico, por conveniencia, con un cuestionario auto-administrado utilizando los recursos de Google Forms. Se promovió la encuesta a través de redes sociales, banners colocados en webs de distintos colaboradores del estudio, invitaciones personales por correo electrónico y listas de distribución de distintas asociaciones profesionales, como la Asociación de Comunicación Política (ACOP) y la promoción de la difusión por parte de socios de la OCPLA (Organización de Consultores Políticos Latinoamericanos), así como listas de envíos de la Fundación Konrad Adenauer. Se recibieron 528 encuestas efectivas.

Las fechas del trabajo de campo se acotaron a los días entre el 14 de marzo y el 14 de mayo de 2016 . Al cerrarse el plazo de recepción de respuestas, se comprobó que la muestra argentina estaba infra-representada en relación con la población total del país y la muestra de España y Venezuela. Así que se realizó un nuevo envío de emails sólo a los públicos objetivos argentinos y se amplió el periodo para estas respuestas hasta el lunes 30 de mayo.

Se distinguieron cuatro tipos de públicos particulares como representantes 
de los actores más interesados e implicados en política, a saber: dirigentes y cargos políticos, consultores políticos, periodistas políticos, y por último, académicos relacionados con la enseñanza e investigación de la política, como podían ser profesores de Ciencias Políticas, Comunicación Política, Derecho político o Derecho Constitucional. El método seleccionado puede condicionar los resultados del estudio, puesto que al elegir un cuestionario online, se presume que las personas que responden a la encuesta constituyen un público más activo en Internet que la media.

La pregunta específica se verbalizó de la siguiente manera: Durante la campaña electoral celebrada en 2015 en su país ¿́cuáles fueron los TRES CANALES PRINCIPALES con los que se informó sobre novedades y eventos políticos? (Señale sólo tres). Limitando las opciones a las tres principales se buscaba averiguar las fuentes y medios habituales, de uso más frecuente, para la obtención de información política, y no los ocasionales o menos relevantes. Las opciones de respuesta fueron: Periódicos impresos, Radio, $T V$ de señal abierta, TV por cable, Publicaciones periodísticas en Internet, Twitter, FaceBook, Youtube, WhatsApp, Cuñas o spots de campaña, Militancia política, Actos de campaña, Conversaciones personales u Otros (especificar).

Para conocer el consumo de medios del público o electorado general se utilizaron encuestas secundarias, tres medios de contraste distintos. Para el caso español, se sirvió de los datos proporcionados por la encuesta del CIS (Centro de Investigaciones Sociológicas) de Febrero 2016, que incluyó una batería de preguntas relativas a los hábitos de uso de las nuevas tecnologías. Para el caso venezolano y argentino se usaron sendas encuestas de opinión pública con dos encuestadores que colaboraron con nuestro estudio y aceptaron incluir en sus estudios de medición de opinión pública dos preguntas similares a las de nuestro cuestionario online. Se trató de la encuestadora de Carlos Fara, con un estudio para el gran Buenos Aires (Octubre 2015), y de la encuestadora Datincorop, de Jesús Seguías, con un sondeo realizado a nivel nacional en Venezuela (Abril 2016).

Las preguntas empleadas para contrastar la población normal con la de los públicos no fueron idénticas en su formulación, y ello implica otra clara limitación metodológica en la medición. Este estudio debe entenderse con sus limitaciones, como una primera aproximación a las diferencias entre los públicos más interesados de la política electoral y el comportamiento más normal de la población electoral.

\section{Análisis y discusión de resultados}

\subsection{Uso de medios en los públicos más interesados en política}

Como puede observarse en el Gráfico 1, los públicos especialmente interesados en política, ante la pregunta "Durante la campaña electoral celebrada en 2015 en su país cंcuáles fueron los TRES CANALES PRINCIPALES con los que se informó sobre novedades y eventos políticos? (Señale solo tres)"; un $61 \%$ afirmaron haberse informado a 
través de Twitter y un $56 \%$ a través de publicaciones periodísticas en Internet. Con un porcentaje menor de respuestas, en una segunda línea de preferencias, se produce prácticamente un cuá- druple empate entre medios preferidos: un 28\% escogieron la TV de señal abierta, un 25,9\% los periódicos impresos, un $25,8 \%$ la radio y un $25,6 \%$ el FaceBook (Gráfico 1).

Gráfico 1. Principales canales usados para informarse políticamente ${ }^{3}$

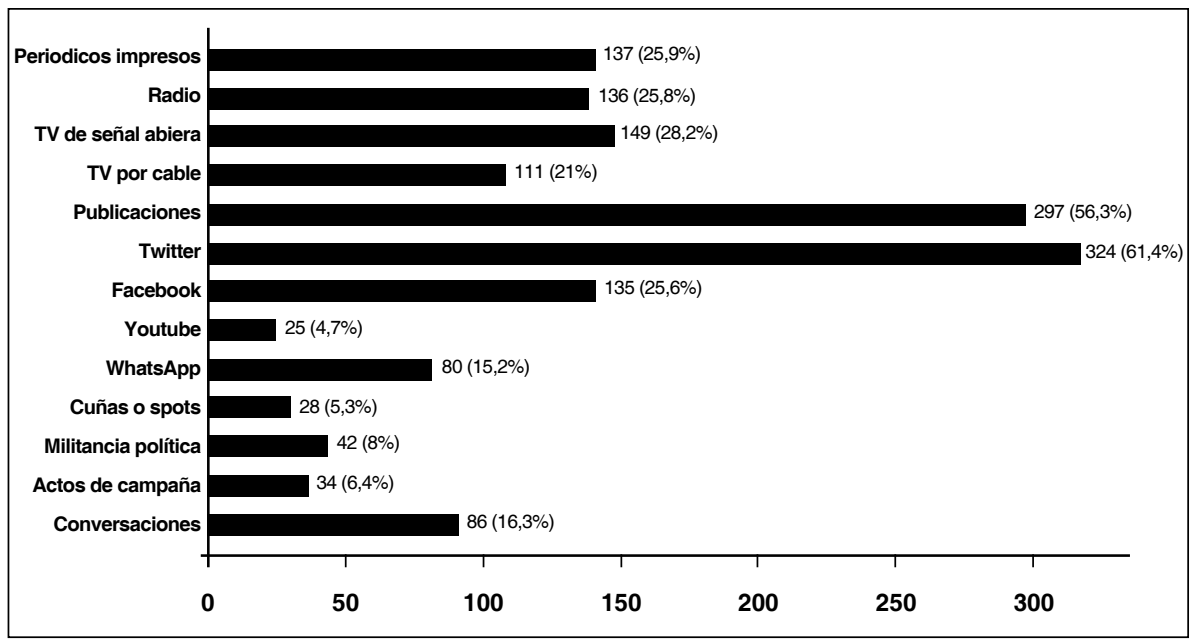

Fuente: Elaboración con datos propios, estudio Ciberpolítica Marzo-Mayo 2016 en relación a los métodos usados por los entrevistados en las elecciones 2015 de Argentina, España y Venezuela, $n=528$

La TV por suscripción fue elegida en un $21 \%$ por estos públicos implicado en política. Menos usados fueron las cuñas o spots electorales $(5,3 \%)$ y aún menos, el uso de una de principales plataformas de difusión de videos, YouTube, con sólo el 4,7\%. Sin embargo, si se suman los porcentajes del consumo de televisión, tanto en suscripción como en señal abierta, alcanza el tercer lugar con un 49,2\%. Es decir, Twitter $(61,4 \%)$, las publicaciones periódicas en la web $(56,3 \%)$ y la TV $(49,2 \%)$ son los tres principales medios que emplearon los agentes especialmente implicados e interesados en política para informarse durante las elecciones de 2015 en Argentina, España y Venezuela.

3 Pregunta completa del cuestionario: Durante la última campaña electoral celebrada en 2015 ¿cómo buscó Ud enterarse de las novedades y eventos? (escoja los tres más importantes). a) Periódicos; b) Radios; c) TV abierta; d)TV por cable; e) Twitter; f) FaceBook; g) YouTube; h) Cuás o spots de campaña; i) Militancia política; j) Actos de campaña; k) Referencias personales. 
Llama la atención cómo entre nuestros entrevistados los medios digitales han superado a los analógicos. La televisión, que había sido el medio de comunicación dominante en las campañas electorales desde su masificación en los años sesenta, pasa en este estudio a un tercer lugar. Los medios corren en plataformas digitales son los canales principales de informarse políticamente. La aparición de Internet ha propiciado nuevas formas de acceso y consumo de la actualidad política (Anduiza, Cristancho \& Cantijoch, 2012). En el estudio sobre la Ciberpolítica de 2006 antes mencionado (Fernández, 2008), los periódicos impresos constituían la fuente principal de información política, preferidos por un $80 \%$ de los encuestados; nueve años más tarde los periódicos en papel merman 50 puntos y dejan de ser la fuente fundamental de información política durante la campaña, superados ampliamente por las distintas plataformas de Internet (que incluyen, eso sí, los periódicos digitales). En dicho estudio anterior, la TV constituía un muy importante medio de información política aún para los públicos especializados. Como se ha comentado, la encuesta puede tener sesgo metodológico que podría privilegiar los métodos digitales como medios de información política, pero al contrastarlo con los datos 2006 la evolución es clara. La investigación de 2006 mostraban que entre este mismo tipo de público, de los más interesados por la política, y utilizando el mismo método de entrevistas autoadministradas online, resultaban claramente dominantes los medios tradicionales, prensa impresa y $\mathrm{TV}$, como métodos primordiales para informarse políticamente (Fernández, 2008).

Las preferencias por canales más ortodoxos y tradicionales de información política en campaña electoral como las conversaciones personales (16\%), aunque sean llevadas a un equivalente digital como WhatsApp $(15,2 \%)$, han sido menos seleccionadas en la multirespuesta de los encuestados. Datos más bajos aún presentan las opciones de militancia política (8\%) o los actos de campaña $(5,6 \%)$. La opción de otros canales apenas fue seleccionado y no tenía relevancia estadística.

Estos datos están en línea con las conclusiones de otras investigaciones que analizaban el perfil de los usuarios que se exponían con mayor intensidad a la información política en Internet, donde el interés por la política es una de las variables más relevantes (Anduiza, Cristancho \& Cantijoch, 2012, p. 680). Se comprueba con estos datos que las personas activas e interesadas en política también participan del "nuevo sistema operativo social" que señalan Rainie y Wellman (2012), porque tienen en Internet su plataforma de contacto e intercambio de información y pueden acceder a ella de manera constante y ubicua, gracias a la comunicación móvil. Nuevas formas de acceder a los contenidos basadas en la movilidad, la inmediatez, la interactividad y la multitarea.

El entorno digital ha propiciado el auge de la Mass selfcommunication (Castells, 2009), una nueva forma social 
de comunicación que, aunque masiva, es producida, recibida y percibida individualmente; y de la que son buena muestra las diversas redes sociales como Twitter. Este uso digital de la información política se convierte en un consumo personalizado y adaptado a los hábitos de una audiencia que también se ha transformado con la revolución de Internet (Medina, 2015). En definitiva, como señala Deuze (2012) ya no se vive “con" los medios, sino más bien "en" los medios.

\subsection{Uso de medios para el activismo en los públicos más interesados en política}

Otra pregunta del cuestionario indagaba en la propia experiencia personal y en la esfera del ciberactivismo. Más que en la infopolítica, exploraba las actividades que el encuestado había realizado de forma personal para activar políticamente durante la campaña. Es decir, aquel uso de medios digitales que implica un mayor grado de compromiso, más allá de la recepción de información. La pregunta era multirespuesta y sin límite de opciones. Las principales respuestas de la categoría fueron " $E n$ Twitter publiqué o hice RT a información politica" (63.4\% de los entrevistados) y "Busqué información en Internet sobre algún candidato a través de Google" (61,9\%).

En un segundo rango de preferencias, como actividad realizada por el $52 \%$ de los encuestados, estuvieron el "Vi videos políticos en línea (YouTube u otros)" y "Recibi y/o envié whatsapps con contenido político". Menos frecuentes fueron el "Visitar el sitio web de un candidato" (44\%), el "Leer un blog sobre candidaturas y/o información política” (40,5\%), el "Compartí en mi muro de FaceBook algún contenido político de mi partido o candidato favorito" (37,7\%), o el "Recibir y/o enviar correos electrónicos de amigos y/o familiares con contenido político" (37\%).

En un tercer rango podríamos ubicar aquellas actividades que hicieron en campaña sólo uno de cada tres, o uno de cada cuatro de nuestros públicos más interesados, como "Recibi correos electrónicos a través de una lista de correo de un partido político o candidato, a la que me había suscrito" (29\%), el "Recibi y/o envié whatsapps con contenido político" (24\%) y otro $24 \%$ afirmó haber participado en una manifestación o encuentro de campaña presencia al que había sido convocado por un correo electrónico.

Con mucha menor frecuencia se encontraron otro tipo de actividades, en teoría importantes para la acción política y la ciberpolítica, como las donaciones pecuniarias y el contacto directo, pero en la práctica raras incluso entre los públicos más interesados en la política, con cerca de un $5 \%$ de incidencia entre nuestras audiencias analizadas. Así apenas un 4,7\% afirmó haber hecho una contribución monetaria en línea a un partido o candidato, y sólo poco más hizo contacto directo, enviándole un email o un mensaje directo con sus preocupaciones a un candidato. 
Gráfico 2. Principales canales usados para activarse políticamente ${ }^{4}$

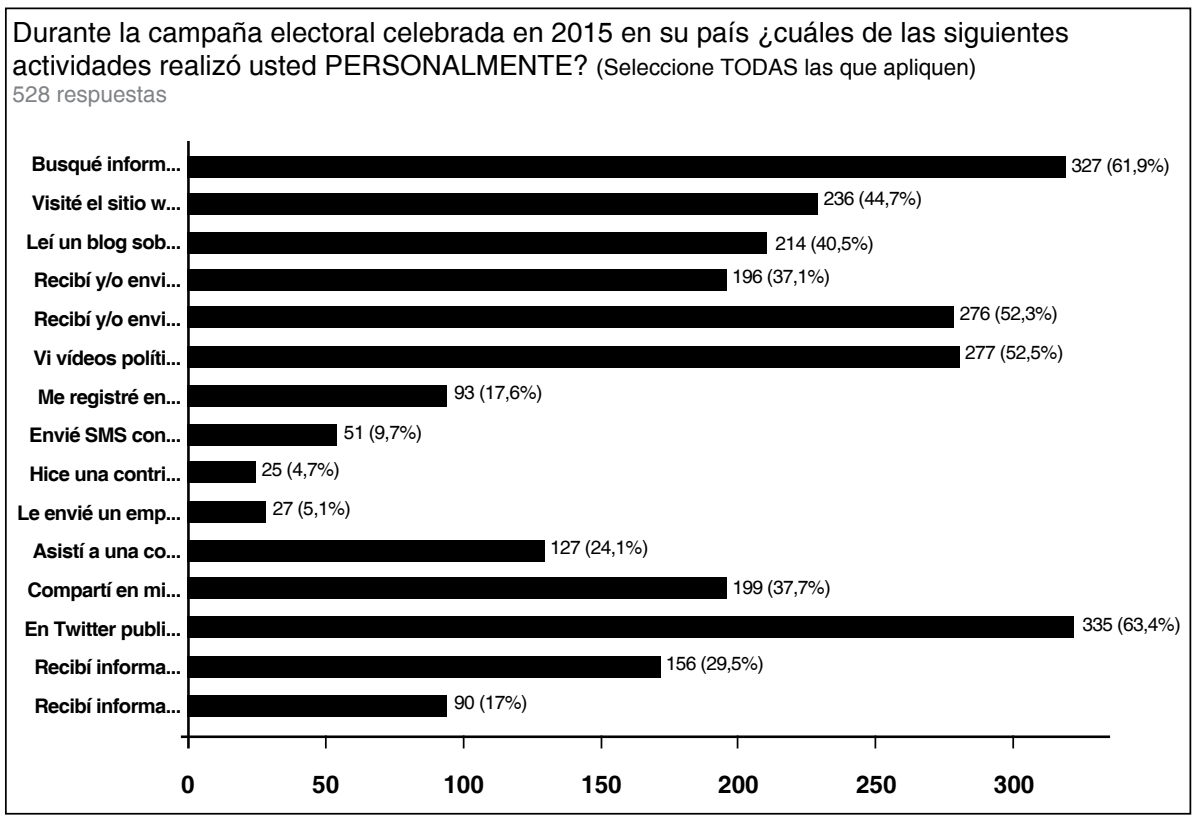

Fuente: Elaboración con datos propios, estudio Ciberpolítica Marzo-Mayo 2016 en relación a los métodos usados por los entrevistados en las elecciones 2015 de Argentina, España y Venezuela, $n=528$

\subsection{Argentina: preguntándole a los electores del Gran Buenos Aires \\ Argentina tiene el nivel más alto de penetración a Internet de la subregión, casi un $80 \%$ en Junio $2016^{5}$, y dentro de \\ la Argentina el Gran Buenos Aires (GBA) es la región con mayor conexión a la Red de redes. Puede suponerse que el uso de los medios digitales para la ci- berpolítica es mayor en el GBA que en el}

4 Opciones completas de respuesta que daba la pregunta en el cuestionario: Durante la última campaña electoral celebrada en 2015 ¿cuál de las siguientes actividades realizó Ud PERSONALMENTE? (Seleccionar todas las que apliquen). A) Busqué información en Internet sobre algún candidato a través de Google: a) Visité el sitio web de un candidato; b) Leí un blog sobre candidaturas y/o información política; c) Recibí y/o envié correos electrónicos de amigos y/o familiares con contenido político; d) Recibí y/o envié whatsapps con contenido político serio; e) Recibí y/o envié whatsapps con contenido político humorístico; f) Me registré en línea a favor de un candidatos y/o me suscribí a una lista de correo de una partidos político o candidato; g) Envié SMS con contenido político; h) Vi videos políticos en línea (YouTube u otros); i) Hice una contribución monetaria en línea a un partido o candidato; j) Le envié un email o un mensaje directo con mis preocupaciones a un candidato envié un email o un mensaje directo con mis preocupaciones a un candidato; k) Asistí a una concentración o manifestación política a la que había sido convocado por un correo-e; l) Compartí en mi muro de FaceBook algún contenido político de mi partido o candidato favorito; $\mathrm{m}$ )En Twitter publiqué o hice RT a información política.

5 Internet World Stats http://www.internetworldstats.com/ 
resto del país. Aún así, cuando comparamos el uso de los medios digitales para informarse y activar políticamente de los electores del Gran Buenos Aires en la elección presidencial del 2015 tenemos un comportamiento muy distinto al de los públicos más interesados en política.

YouTube es el medio digital preferido para informarse de política entre los electores argentinos del GBA (27\%), pero este dato es casi la mitad del que declararon en nuestra encuesta haber "visto videos políticos en línea (YouTube u otros)" entre los interesados en política, con un 52\%. Entre este público más interesado en política, un $37,7 \%$ compartieron información de la campaña en sus muros de FaceBook, pero entre los argentinos del GBA apenas un 21\% recibió información política de la campaña a través de la popular red social.

Quizás lo más llamativo sea el contraste que observamos entre los electores del Gran Buenos Aires y los agentes más interesados en política en lo relativo a Twitter como medio de información política utilizado durante la campaña. Mientras apenas un 5\% de los argentinos del GBA reconocieron usar twitter para informarse de política, entre los más interesados por la política, bien como consultores políticos, académicos de la política, activistas o periodistas políticos llegaba al $61 \%$ los que usaron Twitter para tal fin en las campañas 2015.

El protagonismo de Twitter como herramienta de comunicación política no ha dejado de crecer tanto en Latinoamérica (Fernández, 2012) como en España (Rodríguez y Ureña, 2011). Pero conviene recordar que Twitter no es propiamente un medio de comunicación, sino una plataforma donde los usuarios, individuales o colectivos, comparten y comentan información, en este caso política, con distintos propósitos. Y es que Twitter, como afirma Orihuela, "más allá de la tecnología, son las personas que lo utilizan, los mensajes que se comparten, las conversaciones que se mantienen y las relaciones que se establecen entre sus usuarios" (Orihuela, 2011: 33). En el entorno digital, en general, y en Twitter, en particular, políticos, medios de comunicación y ciudadanos se influyen recíprocamente (López-Meri y Casero-Ripollés, 2016).

Los periodistas han normalizado el uso de Twitter para promocionar su trabajo y rastrear información (Lasorsa, Lewis \& Holton, 2012). Twitter es una vía de acceso a los de medios de comunicación tradicionales en versión digital (prensa, radio y televisión e incluso agencias de noticias), no solo por seguir sus perfiles corporativos, sino también porque la práctica más habitual de los periodistas consiste en enlazar sus contenidos y dirigir el tráfico a las webs de sus medios, e incluso ocasionalmente recomiendan contenidos de la competencia (Noguera, 2013).

También muchos políticos utilizan Twitter, porque en principio les permite dirigirse a audiencias masivas e interactuar con el electorado sin la mediación de los periodistas (Casero-Ripollés, 2008), generar noticias y ganar presencia en los medios, en un intento de anteponer su lógica a la lógica mediática (Strömbäck, 2008; López-Meri, 2016), e incluso para controlar el discurso público (Broersma \& Graham, 2013). 
Sin embargo, nuestro estudio sugiere que el uso de Twitter como instrumento de la infopolítica y ciberpolítica entre los ciudadanos es mucho menos relevante que entre los públicos especialmente interesados. El caso argentino es elocuente al respecto. Pese a que los electores comentan los asuntos políticos en Twitter (Gainous \& Wagner, 2014; Parmelee \& Bichard, 2012), o monitorizan a la clase política, filtrando y jerarquizando infor- mación (Bruns \& Highfield, 2015); nuestra encuesta evidencia que estos usos no son cuantitativamente comparables a los de otro tipo de audiencias. Desde herramientas como Twitter, los ciudadanos con inquietudes políticas pueden acceder a la esfera de la comunicación tradicional e intentar influir en políticos y medios (Chadwick, 2013), pero esta posibilidad parece darse en proporciones mínimas entre el elector corriente.

Gráfico 3. Uso de las redes sociales para informarse políticamente entre electores bonaerenses ${ }^{6}$

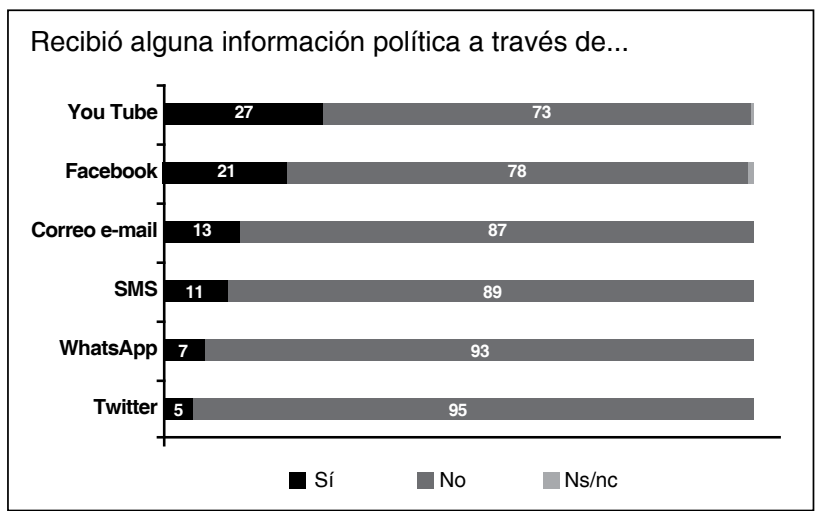

Fuente: Fara y Asociados, encuesta en Gran Bs. Aires, con verbatim de Carmen Beatriz Fernández

\subsection{En España, unos son de Twitter y otros, de FaceBook}

El Centro de Investigaciones Sociológicas (CIS) estudia las variaciones de la opinión pública española desde 1963. Realiza encuestas periódi- cas, normalmente un barómetro de frecuencia bimestral, y coloca los datos obtenidos a disposición del público desde su página web. Los cuestionarios guardan un diseño estándar pero no son idénticos, sino que a partir de

6 Ficha técnica de la encuesta CARLOS FARA Y ASOCIADOS. Universo: Argentinos mayores de 16 años en condiciones de votar en Gran Buenos Aires. Muestra y Cobertura: 316 casos. Fecha de Relevamiento: Del 17 al 19 de octubre de 2015. Técnica de Muestreo: Semi-probabilística. Relevamiento domiciliario en GBA. Cuotas por sexo y edad. Margen de Error Estimado: +/- $5.5 \%$. Nivel de Confianza: $95 \%$ 
un mismo esqueleto añaden distintos temas y preguntas. En el instrumento de Febrero 2016, posterior al proceso electoral del año 2015, se incluyó una batería de preguntas relativa al uso de los medios digitales y redes sociales.

Al comparar los públicos españoles interesados (consultores, académicos, periodistas y políticos) con la población en general, se comprueba un patrón de consumo de la información política distinto, no solo en penetración de las herramientas sino también en su intensidad. En cuanto al uso de medios, los españoles mantienen a la televisión como el medio de comunicación preferente para obtener información política frente a los interesados que lo relegaban a un tercer lugar.

Pero también hay diferencias en la intensidad, por ejemplo en las redes sociales. Según la encuesta CIS de Marzo 2016, el 46,3\% de los españoles utilizó la redes sociales, mientras que entre los encuestados españoles con alta implicación política, el 76,8\% revisó la red social que mostró un uso más intenso (Twitter) varias veces al día.

Cuadro 2. Uso de las redes sociales entre españoles ${ }^{7}$

\section{Pregunta 19}

A continuación vamos a realizarle una serie de preguntas relacionadas con las tecnologías de la comunicación. ¿Podría decirme si ha utilizado en los últimos 6 meses...?

\begin{tabular}{|l|c|c|c|c|c|c|}
\hline \multicolumn{1}{|c|}{ TIC } & Sí & No & $\begin{array}{c}\text { No sabe } \\
\text { lo que es }\end{array}$ & N.R. & N.C. & (N) \\
\hline Teléfono móvil (llamadas y/o sms) & 90,8 & 9,2 & - & - & - & $(2,478)$ \\
\hline Correo electrónico (e-mail) & 55,8 & 43,3 & 0,7 & 0,1 & 0,1 & $(2,478)$ \\
\hline $\begin{array}{l}\text { WhatsApp u otra aplicación (Line, } \\
\text { Telegram, Snapchat) }\end{array}$ & 70,2 & 28,9 & 1,0 & - & - & $(2,478)$ \\
\hline $\begin{array}{l}\text { Redes sociales virtuales } \\
\text { (Facebook, Twitter, Linkedln, etc.) }\end{array}$ & 46,3 & 52,2 & 1,3 & 0,1 & 0,1 & $(2,478)$ \\
\hline
\end{tabular}

Fuente: CIS Febrero 2016, $n=2.478$

7 Ficha Técnica de la encuesta CIS № 3128 BARÓMETRO DE FEBRERO. Ámbito: Nacional. Universo: Población española de ambos sexos de 18 años y más. Tamaño de la muestra: Diseñada: 2.500 entrevistas. Realizada: 2.478 entrevistas. Afijación: Proporcional. Ponderación: No procede. Puntos de Muestreo: 256 municipios y 46 provincias. Muestreo: Polietápico, estratificado por conglomerados, con selección de las unidades primarias de muestreo (municipios) y de las unidades secundarias (secciones) de forma aleatoria proporcional, y de las unidades últimas (individuos) por rutas aleatorias y cuotas de sexo y edad. Los estratos se han formado por el cruce de las 17 comunidades autónomas, con el tamaño de hábitat, dividido en 7 categorías: menor o igual a 2.000 habitantes; de 2.001 a 10.000; de 10.001 a 50.000; de 50.001 a 100.000; de 100.001 a 400.000; de 400.001 a 1.000 .000 , y más de 1.000 .000 de habitantes. Los cuestionarios se han aplicado mediante entrevista personal en los domicilios. Error muestral: Para un nivel de confianza del $95,5 \%$ (dos sigmas), y $P=Q$, el error real es de $\pm 2,0 \%$ para el conjunto de la muestra y en el supuesto de muestreo aleatorio simple. Fecha de realización: Del 1 al 11 de febrero de 2016. 
Cuando el CIS español indaga sobre las redes sociales relacionadas con las tecnologías de la comunicación de la pregunta anterior (Cuadro 2), lo pregunta de manera genérica, agrupando FaceBook, Twitter, LinkedIn y otras dentro de la misma categoría de respuesta. Y poco menos de la mitad de los encuestados utilizan las redes sociales en España. Sin embargo, otra pregunta del CIS interroga sobre las redes sociales favoritas (Cuadro 3). Entre los ciudadanos españoles, FaceBook mo- nopoliza la preferencia de las redes sociales, pues un $91,5 \%$ de los encuestados la señalan como favorita. El CIS no indaga específicamente si se utiliza o no el FaceBook como fuente de información política, sin embargo esta preferencia es muy llamativa al contrastarla con la de los públicos más especializados. En nuestra encuesta a ese público especialmente interesado, FaceBook adquirió una importancia relativa menor en las elecciones españolas con apenas un $4 \%$.

Cuadro 3. Entre españoles conectados a redes sociales, ¿Cuáles son sus redes favoritas?

Pregunta 33

¿Qué red social utiliza principalmente en internet? ¿Y en segundo lugar? ¿Y en tercer lugar? (RESPUESTA ESPONTÁNEA)

\begin{tabular}{|l|r|r|r|}
\hline Red Social & Principalmente & Segundo lugar & Tercer lugar \\
\hline Facebook & 91,5 & 3,9 & 0,3 \\
\hline Twitter & 3,8 & 18,3 & 2,9 \\
\hline Google Plus (+) & 0,9 & 3,5 & 1,0 \\
\hline Linkedln & 1,0 & 2,3 & 2,4 \\
\hline Instagram & 1,9 & 10,9 & 7,1 \\
\hline Badoo & - & 0,3 & 0,3 \\
\hline Flickr & - & - & 0,2 \\
\hline Fotolog & - & - & 0,1 \\
\hline MySpace & - & 0,1 & 0,1 \\
\hline Tuenti & - & 0,7 & 1,1 \\
\hline Xing & - & - & 0,1 \\
\hline Otra & - & 2,4 & 1,7 \\
\hline Snapchat & 0,1 & 0,1 & 0,5 \\
\hline Pinterest & - & - & 0,3 \\
\hline FaceTime & - & - & 0,1 \\
\hline Telegram & - & - & 0,2 \\
\hline Ask & - & - & 0,1 \\
\hline N.C. & $(1,148)$ & $(1,148)$ & $(1,148)$ \\
\hline (N) & & & \\
\hline
\end{tabular}


Ya entre los ciudadanos que son usuarios de redes sociales, sólo la mitad, un $49,8 \%$, las revisa con frecuencia (bien continuamente o bien varias veces al día) (CIS marzo 2016, cuadro 4). Es decir, apenas un $23 \%$ de la población en general revisa varias veces al día alguna de sus redes sociales, cifra muy distinta a la obtenida en nuestro estudio de los públicos especializados, que la triplica, alcanzando hasta el $77 \%$ (gráfico 4). No solo nuestros entrevistados españoles son distintos de la población en general, cosa que cabría esperarse, sino que también son distintos a los usuarios de redes sociales, y expresan un uso mucho más intensivo de los medios digitales en general, y de las redes sociales en particular, como vehículos útiles para informarse políticamente.

Cuadro 4. Entre españoles conectados a redes sociales, ¿Con qué frecuencia suele conectarse?

\begin{tabular}{|l|r|}
\hline Continuamente & 16,7 \\
\hline Varias veces al día & 33,1 \\
\hline Una vez al día & 25,3 \\
\hline De tres a cinco veces por semana & 10,5 \\
\hline De una a dos veces por semana & 7,2 \\
\hline Cada varias semanas & 2,5 \\
\hline Casi nunca & 3,9 \\
\hline N.C. & 0,7 \\
\hline (N) & $(1.148)$ \\
\hline
\end{tabular}

Fuente: CIS Febrero 2016, $n=1.148$

Gráfico 4. Revisión del Twitter entre españoles especialmente interesados en la política,

"Recordando los últimos días, ¿̇con qué frecuencia revisó Ud Twitter?

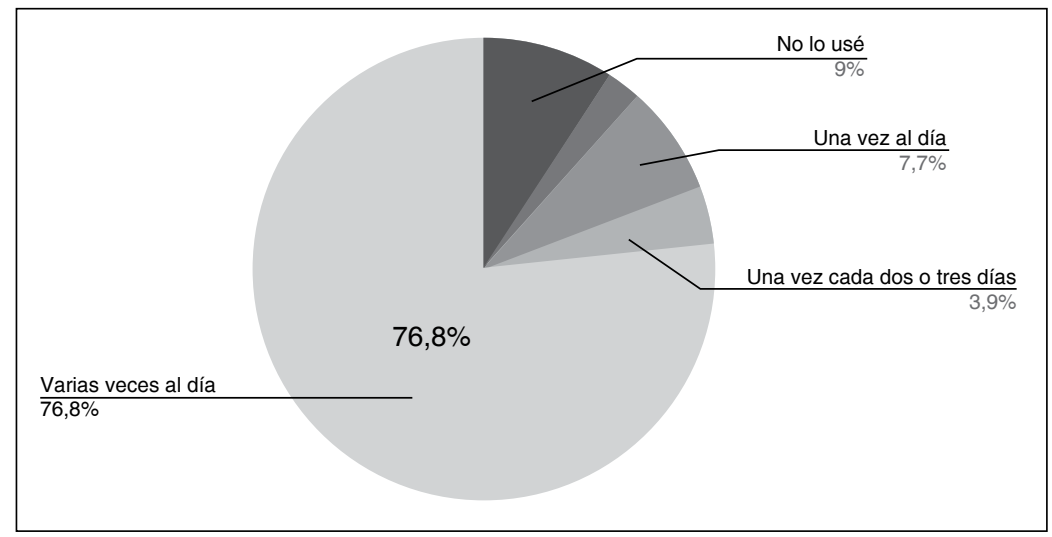

Fuente: Datos propios del estudio Ciberpolítica 2015, n=155 respuestas españolas del total de 538 
El resultado es distinto cuando se compara los hábitos respecto a la mensajería instantánea entre los distintos tipos de usuarios. El empleo masivo de mensajería instantánea para comunicarse entre los españoles, hace que la población especialmente interesada en política sea mucho más parecida a la población en general. Entre nuestros encuestados especialistas en política de
España un $88,5 \%$ revisa su WhatsApp varia veces al día. La encuesta CIS de Febrero encontró que entre los españoles en general un $70,2 \%$ usan el WhatsApp o alguna otra aplicación equivalente (Line, Telegram $\mathrm{u}$ otras plataformas son incluidas como opción de respuesta, aunque WhatsApp monopoliza el $98.1 \%$ de las preferencias) (Cuadro 5).

Cuadro 5. Plataformas utilizadas entre españoles que usan mensajería instantánea ¿Y qué aplicaciones de mensajería instantánea utiliza más frecuentemente? ¿Y en segundo lugar? ¿Y en tercer lugar?

\begin{tabular}{|l|c|c|c|}
\hline Plataformas & Principalmente & Segundo lugar & Tercer lugar \\
\hline WhatsApp & 98,1 & 0,7 & 0,1 \\
\hline Skype & 0,3 & 9,1 & 3,2 \\
\hline Telegram & 0,2 & 3,5 & 0,5 \\
\hline Line & 0,1 & 2,5 & 1,3 \\
\hline Chat de Facebook & 0,5 & 14,3 & 4,5 \\
\hline Otra & - & 1,4 & 0,9 \\
\hline Twitter & - & 0,2 & 0,1 \\
\hline Hangouts & - & 0,2 & 0,2 \\
\hline Messenger & 0,1 & 0,1 & 0,1 \\
\hline WeChat & - & 0,1 & - \\
\hline Instagram & - & 0,2 & 0,2 \\
\hline FaceTime & - & 0,1 & - \\
\hline Viber & - & 0,1 & 0,1 \\
\hline BlackBerry Messenger & - & - & 0,1 \\
\hline N.S. & 0,2 & 8,1 & 4,5 \\
\hline N.C. & 0,6 & 59,5 & 84,2 \\
\hline (N) & $(1,739)$ & $(1,739)$ & $(1,739)$ \\
\hline
\end{tabular}


Cuadro 6. Entre españoles que usan mensajería instantánea, ¿Con qué frecuencia suele revisar los mensajes?

¿Con qué frecuencia consulta sus mensajes de WhatsApp u otra aplicación de mensajería instantánea?

\begin{tabular}{|l|r|}
\hline Continuamente & 42,3 \\
\hline Varias veces al día & 47.4 \\
\hline Una vez al día & 6,4 \\
\hline De tres a cinco veces por semana & 1,2 \\
\hline De una a dos veces or semana & 0,6 \\
\hline Cada varias semanas & 0,2 \\
\hline Casi nunca & 1,0 \\
\hline N.C. & 0,8 \\
\hline (N) & $(1.739)$ \\
\hline
\end{tabular}

Fuente: CIS Febrero 2016, $n=1.739$

Es decir, un $68.8 \%$ de los españoles usan la plataforma WhatsApp para comunicarse de manera instantánea con sus allegados y de ellos el $89,7 \%$ lo hacen frecuentemente (bien continuamente o bien varias veces al día). Al comparar este dato con el encontrado al indagar sobre los hábitos de los públicos más interesados en la política encontramos un comportamiento muy similar (Gráfico 5).

Gráfico 5. Revisión del WhatsApp entre españoles especialmente interesados en la política, "Recordando los últimos días, ¿̇con qué frecuencia revisó Ud su WhatsApp?"

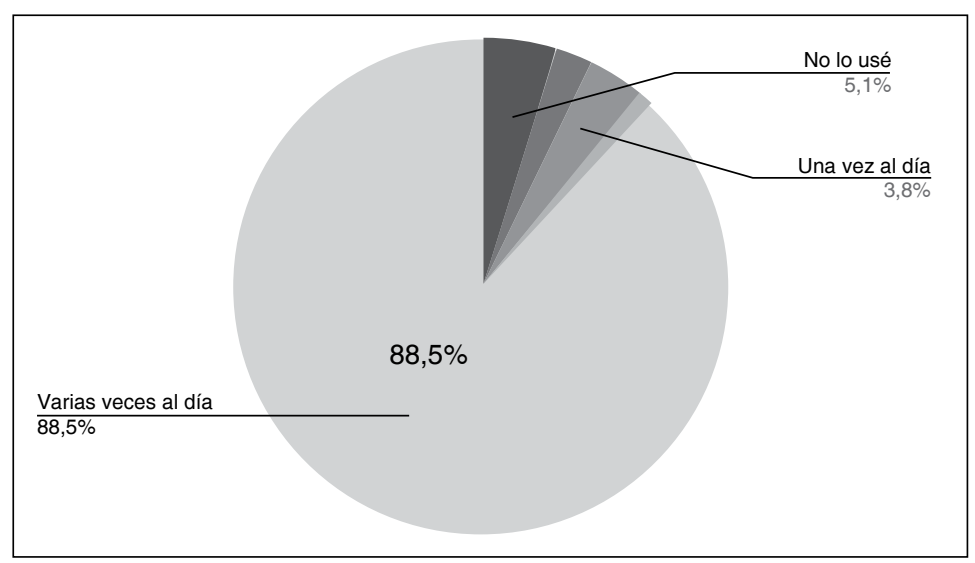

Fuente: Datos propios del estudio Ciberpolítica 2015, n=155 respuestas españolas del total de 538 
En definitiva, a diferencia de lo que ocurre con las redes sociales (FaceBook, Twitter y otras) en las que el comportamiento del elector normal es distinto y menos intenso que el de los especialmente interesado en política, en España los públicos más interesados en la política utilizan las plataformas de comunicación instantánea de forma similar y tan intensa como cualquier otro usuario del WhatsApp.

Otro elemento interesante para el análisis, y en el cual nuestros públicos especialistas no resultan tan "rara avis" es el lo relativo al ciberactivismo. De acuerdo a la encuesta CIS un 6\% de la ciudadanía habría usado herramientas 2.0 para contactar directamente con algún político, cifra ésta muy parecida al $5,1 \%$ de nuestra encuesta en públicos especializados que expresó haberlo hecho. El 9\% del electorado expresó para el CIS haber realizado alguna contribución monetaria a través de canales digitales, cifra más generosa a la del 4,7\% que hacen lo propio, entre los consultores, académicos, periodistas y políticos.

Vuelve a saltar la diferencia con los electores corrientes al comparar su participación en "listas". Un $13 \%$ manifiesta haberse suscrito a una lista de distribución de información (Cuadro 7), cifra que encontramos más que duplicada entre las audiencias estudiadas en la encuesta online, donde "Recibí correos electrónicos a través de una lista de correo de un partido político o candidato, a la que me había suscrito" es señalado por un $29 \%$ entre el público más interesado.

Cuadro 7. Uso de herramientas para el ciberactivismo entre españoles que usan mensajería instantánea

\section{Pregunta 42}

En los últimos doce meses, ¿ha utilizado alguna vez las tecnologías de la comunicación (teléfono móvil, correo electrónico, WhatsApp u otra aplicación de mensajería instantánea y redes sociales) para...?

\begin{tabular}{|l|c|c|c|c|}
\hline Tecnologías de la Comunicación & Sí & No & N.C. & (N) \\
\hline $\begin{array}{l}\text { Contactary/o comunicarse con algún/a político/a (diputado/a, } \\
\text { concejal/a, senador/a) o partido político }\end{array}$ & 6,3 & 92,3 & 1,4 & $(2,264)$ \\
\hline $\begin{array}{l}\text { Contactar y/o comunicarse con alguna asociación u } \\
\text { organización (cultural, deportiva, profesional, etc.) }\end{array}$ & 21,9 & 76,8 & 1,4 & $(2,264)$ \\
\hline $\begin{array}{l}\text { Suscribirse a una lista de distribución sobre temas de } \\
\text { actualidad para recibir documentos, peticiones y/o campañas }\end{array}$ & 13,0 & 85,4 & 1,6 & $(2,264)$ \\
\hline $\begin{array}{l}\text { Escribir comentarios sobre temas de actualidad, sociales o } \\
\text { políticos en algún foro, blog, red social, etc. }\end{array}$ & 18,8 & 79,7 & 1,5 & $(2,264)$ \\
\hline Realizar una donación a alguna asociación u organización & 9,1 & 89,2 & 1,7 & $(2,264)$ \\
\hline Firmar uan petición o adherirse a un manifiesto o campaña & 17,7 & 80,8 & 1,5 & $(2,264)$ \\
\hline $\begin{array}{l}\text { Participar en la convocatoria de una manifestación o acto } \\
\text { reivindicativo }\end{array}$ & 7,3 & 90,9 & 1,9 & $(2,264)$ \\
\hline
\end{tabular}




\subsection{Venezuela: todos los venezolanos} migran de medios, pero la preferencia política marca una diferencia

Con posterioridad a la elección legislativa se preguntó a los electores, en una encuesta de alcance nacional, cuál había sido el medio de comunicación más usado para informarse del acontecer electoral (Datincorp, Mayo 2015). En Venezuela, la TV sigue siendo el medio principal escogido por los electores normales para informarse políti- camente, con un $26 \%$ de los electores informándose a través de la TV de señal abierta, con contenidos controlados en mayor o menor medida por el gobierno nacional. Sin embargo un número similar (23\%) lo hace a través de canales de cable, o TV por suscripción, que incluye cadenas de producción extranjeras, como CNN, TVE y Antena 3. Las redes sociales y las publicaciones en internet alcanzan en conjunto otro importante $26 \%$.

Gráfico 6. Venezuela 2016 ¿Durante las pasadas elecciones parlamentarias cuál fue el canal que más usó para informarse sobre el proceso electoral? ${ }^{8}$

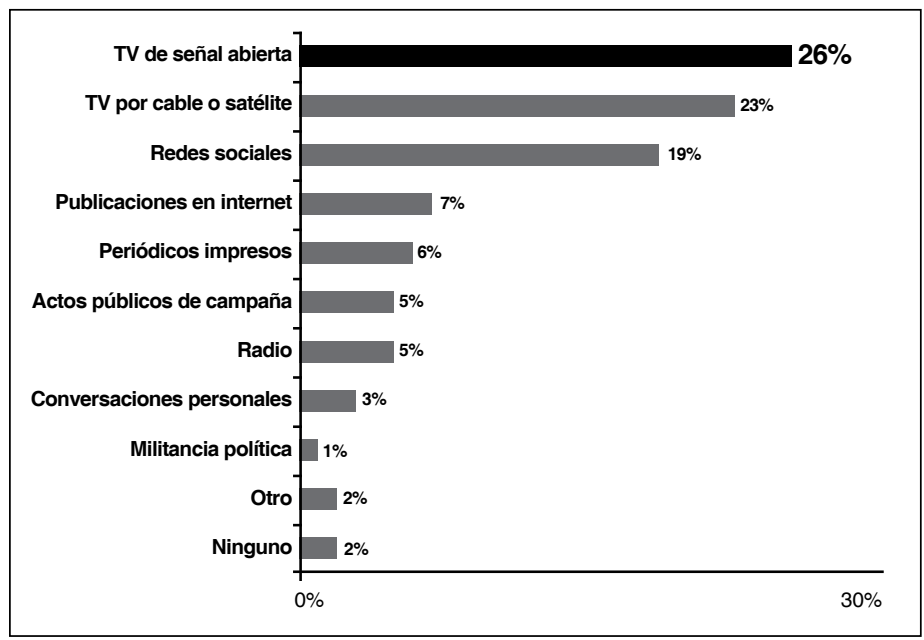

Fuente: Datincorp Venezuela, con verbatim de Carmen Beatriz Fernández, Abril 2016

8 Ficha Técnica de la Encuesta DATINCORP. Universo: electores de la República Bolivariana de Venezuela, mayores de 18 años de edad, residentes en Venezuela. Alcance Geográfico: dominios urbanos mayores y algunos dominios urbanos menores de los mencionadas áreas político-administrativas. Método: La muestra fue diseñada bajo el método probabilístico tetraetápico (comenzando con la selección de las áreas urbanas, luego las selección de las manzanas y calles, la selección de las viviendas, y finalmente la selección de los entrevistados), tomando en consideración las desagregaciones planteadas en la cobertura. Tamaño: El tamaño " $n$ " global y final de la muestra fue de 1.207 electores entrevistados. Error máximo muestral esperado de (+-) 2,8\%, y con un Nivel de Confianza del 95\%. Estrategia de Campo: Se entrevistaron a las personas preseleccionadas estrictamente en sus hogares, clasificándolos por Tipo de Vivienda, Edad y Sexo. Fecha: La investigación de campo concluyó el 10 de Abril de 2016. 
Este claro predominio de la TV, en la que casi la mitad de los electores del país expresan su preferencia por la pequeña pantalla a la hora de informarse sobre las novedades político electorales, es un indicador en franco contraste con los datos obtenidos por nuestra encuesta de los públicos particularmente interesados en el mundo de la política, pues el consumo de TV de los electores triplica la frecuencia obtenida para los públicos especializados (Cuadro 8). En efecto, en nuestra encuesta a consultores, académicos, periodistas y políticos, las redes sociales cobran importancia primordial (34\%), desbancando a la TV como principal fuente informativa $(14 \%)$, que pasa a un lejano tercer lugar, por detrás de las publicaciones periodísticas en Internet (18\%).

Cuadro 8. Venezuela 2015, Comparación entre los electores y los públicos más interesados

\begin{tabular}{|l|c|c|}
\hline \multicolumn{1}{|c|}{ Mezcla de medios } & Ven electores & $\begin{array}{c}\text { Ven }+ \\
\text { interesados }\end{array}$ \\
\hline Actos y militancia & $6 \%$ & $6 \%$ \\
\hline Redes sociales & $19 \%$ & $34 \%$ \\
\hline TV (abierta y por cable) & $49 \%$ & $14 \%$ \\
\hline Radio & $5 \%$ & $7 \%$ \\
\hline Prensa en Internet & $7 \%$ & $18 \%$ \\
\hline Periódicos impresos & $6 \%$ & $5 \%$ \\
\hline Conversaciones personales & $3 \%$ & $7 \%$ \\
\hline
\end{tabular}

Fuente: Elaboración propia contrastando datos de Encuesta Ciberpolítica 2015 con Datincorp Venezuela, encuesta nacional, Abril 2016

En Venezuela, tan interesante como identificar los contrastes entre los ciudadanos electores y los públicos especializados, es analizar los datos de infopolítica ciudadana cruzados en función de las preferencias políticas del elector, como ya apuntábamos en el artículo previo (Rodríguez-Virgili y Fernández, 2017). Al hacerlo encontramos que los canales de TV cuyo manejo editorial está dominado por el gobierno son utilizados como medio de información política fundamentalmente por quienes son partidarios del gobierno. Mientras un $36 \%$ de los partidarios del oficialismo (en negro en el gráfico 7) usan la TV de señal abierta como canal de información política principal, sólo un $17 \%$ de los partidarios de la oposición hacen lo propio, y un $33 \%$ de quienes se perciben a sí mismos como "neutros" o "no-alineados" (en gris). En relación a las redes sociales como principal medio de información política ocurre exactamente lo opuesto: un $26 \%$ de los opositores se informan políticamente a través de RRSS, mientras que sólo un $8 \%$ de los oficialistas hacen lo propio. 
Estos resultados confirman la teoría de la exposición selectiva. Esta teoría afirma que el consumo de los medios está determinado por las predisposiciones de la audiencia, que busca confirmar o reforzar sus opiniones en los contenidos de los medios (Lazarsfeld, Berelson y Gaudet, 1948). Es decir, los ciudadanos buscan en la información la mayor consonancia posible con sus ideas previas sobre la realidad (Stroud, 2010). El retorno a la teoría de la exposición selectiva en el contexto anglosajón, que también se ha detectado en España (Berganza y Martín, 2001; Humanes, 2014), se fundamenta en dos premisas: la multiplicación de canales para obtener información y la aparición de un modelo de periodismo alejado de la objetividad, que permite la exposición partidista (Goldman y Mutz, 2011; Stroud, 2011). Ambas premisas se cumplen también en el caso Venezolano en las elecciones de 2015 que se analiza en el presente estudio.

Gráfico 7. Venezuela 2016, discriminada por preferencias políticas ¿Durante las pasadas elecciones parlamentarias cuál fue el canal que más usó para informarse sobre el proceso electoral?

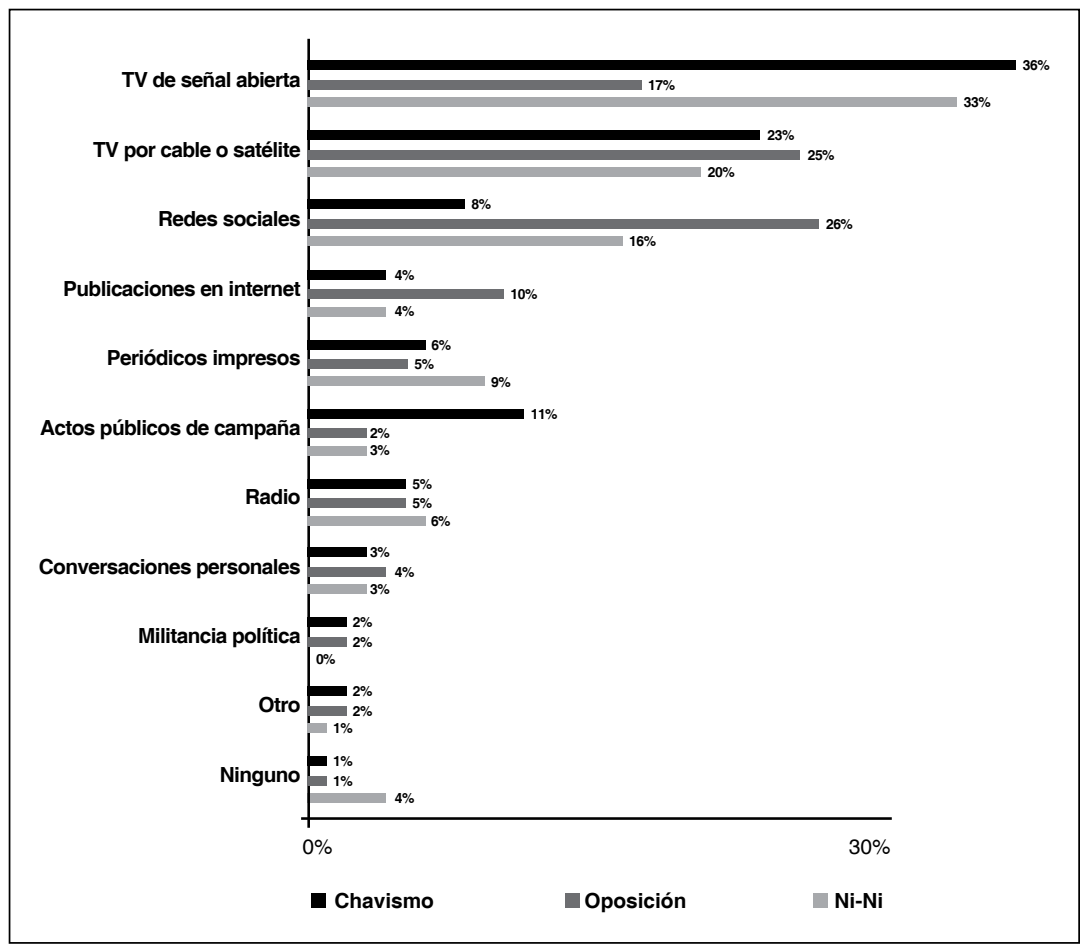

Fuente: Datincorp Venezuela, encuesta nacional, con verbatim sugerido por Carmen Beatriz Fernández, Abril 2016, $n=1.207$ 


\section{Conclusiones}

Esta investigación trata de averiguar la manera en que se informan los actores especialmente implicados e interesados en política durante el periodo electoral y contrastarla con la forma en que lo hacen los electores corrientes. Para ello, se obtuvieron datos primarios y se ha analizado el uso de medios por parte de cargos políticos, periodistas políticos, profesores de materias relacionadas con la política y consultores políticos en tres elecciones críticas, las de Argentina, España y Venezuela en 2015, y se ha comparado con datos secundarios del uso de medios por parte de la población normal, procedentes de tres distintas fuentes externas. Como se señaló en su lugar, se presenta un análisis de carácter preliminar, donde el uso de datos procedentes de fuentes diversas resta estandarización e implica una debilidad del estudio, de forma que impide sacar conclusiones definitivas.

Con toda la cautela, tras el análisis de los datos de los tres casos, puede afirmarse como una primera conclusión que debe considerarse como hipótesis razonable que los públicos especialistas, sus hábitos y fuentes de información política durante la campaña electoral difieren de manera notable con los de los electores en general. En ninguno de los tres casos son comparables las poblaciones integradas por los públicos especialmente interesados en política con los ciudadanos. Este supuesto razonable que refuerza este estudio debe de constatarse en futuros trabajos.

Como segunda conclusión, se observa un desplazamiento del centro de gravedad de las campañas hacia el mundo digital, que a su vez responde a los cambios en los hábitos del consumidor global hacia los medios de comunicación digitales. La comparación entre nuestros estudios en ciberpolítica 2006 y 2015 identifican ese desplazamiento (Fernández, 2008). Esto se advierte tanto en los públicos especializados como en la población electoral normal. Por tanto, se constata que también en la información política se avanza hacia la convergencia mediática y se consolida un sistema híbrido de comunicación (Chadwick, 2013), del que participan -y se interrelacionan constantementetanto los medios analógicos como los digitales y en el que las variables relacionadas con las preferencias personales, necesidades y expectativas son relevantes para explicar el consumo de información.

Este desplazamiento que refuerza lo digital como entorno de información política dominante acelera los tiempos de la política y tiene serias implicaciones para los costos de las campañas. Resulta llamativo que pese a que encontremos un patrón distinto de consumo de la información entre la ciudadanía y los públicos especializados, en lo que respecta a la inmediatez de la información, al uso de la mensajería instantánea, los hábitos de uso sean similares. Sobre todo en España, donde el empleo masivo de mensajería instantánea para comunicarse entre los electores corrientes coincide con el hábito de uso de los públicos especialistas. En consecuencia, cabe preguntarse hasta qué punto ambos elementos, el de la 
velocidad de transmisión de la información y el de la incidencia de los nuevos formatos en los presupuestos de campaña, inciden en la volatilidad de la política y en el carácter vertiginoso con que se producen los cambios políticos en las tres sociedades estudiadas: Argentina, España y Venezuela.

El fenómeno de la mayor importancia relativa de los medios digitales es coincidente en los tres países analizados, aunque con diferencias, pues el fenómeno parece apreciarse de forma más intensa y acelerada en Venezuela. En el caso particular de Venezuela la migración de las audiencias del mundo analógico al digital combina la tendencia general global con lo que se entiende como una respuesta deliberada de las audiencias en rebeldía ante las ambiciones de control de la información del gobierno nacional. El uso intensivo de la política 2.0 en Venezuela está relacionado con la consolidación de la llamada "hegemonía comunicacional" que buscaba desde el gobierno el control de los medios de comunicación, en clara constatación de la teoría de la exposición selectiva. Sin embargo, precisamente por ello, resulta por demás llamativo que entre el elector corriente continúe siendo la TV la "prima donna" de los medios informativos.

Como tercera conclusión, puede apuntarse que la migración hacia lo digital pareciera ser más acelerada entre los públicos especializados, que entre los electores corrientes. Los datos del análisis descriptivo indican que Twitter, las publicaciones periódicas en la web y la señal abierta de TV son los tres princi- pales medios que emplearon los agentes especialmente implicados e interesados en política para informarse durante las elecciones objeto de estudio. Pero incluso en esa adaptación a la convergencia mediática, se producen llamativas divergencias, porque los electores en general usan FaceBook y WhatsApp con intensidad y, sin embargo parecen poco relevantes cuando se analizan desde la dimensión infopolítica y de ciberactivismo en las campañas. $O$ por lo menos en la importancia relativa que los públicos especializados le asignan. El caso más llamativo en estas diferencias es el español, donde los públicos especialmente interesados en política utilizan con gran asiduidad Twitter mientras los electores españoles prefieren FaceBook. En Argentina, el $61 \%$ de los especialmente interesados en política utiliza Twitter, mientras solo el $5 \%$ de los electores argentinos encuestados reconocía usar esta red social.

Con estas primeras conclusiones, parece pertinente seguir investigando sobre las diferencias entre ambas poblaciones analizadas e interpretar qué significan esas desigualdades en términos de los respectivos marcos de referencia. ¿Qué implicaciones tiene que quienes tengan a la política como oficio posean tan distintos hábitos informativos respecto al electorado? ¿Es relevante que quienes ejercen el periodismo político prioricen sus fuentes informativas de manera distinta a la de la ciudadanía ? ¿Se trata simplemente de una observación relacionada con una mayor intensidad de uso vinculada a los sesgos profesionales de los públicos 
estudiados que no tiene mayor importancia cualitativa? o, por el contrario, ¿puede ocurrir que el patrón tan distinto de las fuentes informativas derive en la generación de marcos de interpretación de la realidad muy distintos entre los electores "normales" y los públicos especialmente involucrados con el mundo de la política? Porque la presente investigación sugiere que pese a la rápida aceptación que ha tenido lo digital en el mundo de la información, es posible que se esté haciendo poco periodismo y escasa campaña electoral allí donde están las audiencias, FaceBook y WhatsApp, e incluso, en el ámbito académico, no se investiga lo suficiente en las plataformas sociales preferidas por el elector medio.

Sin duda, habrá que seguir profundizando en el estudio de la infopolítica y comprobar en futuras investigaciones ver si se reafirman o refutan las tendencias detectadas

\section{Referencias Bibliográficas}

Anduiza, E., Cristancho, C. y Cantijoch, M. (2012). La exposición a información política a través de Internet. Arbor, 188 (756), pp. 673-688.

Arterton, F. C. (1987). Teledemocracy: can technology protect democracy? Newbury Park, Calif: Sage Publications.

Berganza, R. y Martín Llaguno, M. (2001). Votantes y medios de comunicación en las elecciones nacionales españolas de 1996: ¿exposición selectiva o influencia mediática? Comunicación y Sociedad, Vol. 14(1), pp. 51-70.

Bowman, S. y Willis , C. (2003). We Media. How audiences are shaping the future of news and information. Virginia: J.D. Lasica. Disponible en http://www.hypergene.net/wemedia/download/we_media.pdf

Broersma, M. y Graham, T. (2013). Twitter as a News Source: How Dutch and British Newspapers used tweets in the news coverage, 2007-2011. Journalism Practice, 7 no 4, pp. 446-464.

Bruns, A. y Highfield, T. (2015). From news blogs to news on Twitter: gatewatching and collaborative news curation. En: Coleman, S. y Freelon, D. (Eds.), Handbook of Digital Politics, pp. 325-339.

Casero-Ripollés, A. (2008). Modelos de relación entre periodistas y políticos: La perspectiva de la negociación constante. Estudios sobre el Mensaje Periodístico, 14, pp. 111-128.

Castells, M. (2009). Comunicación y poder. Madrid: Alianza Editorial.

Chadwick, A. (2013). The Hybrid Media System. Politics and Power. Nueva York: Oxford University Press.

Dahlgren, P. (2005). The Internet, Public Spheres, and Political Communication: Dispersion and Deliberation. Political communication, vol. 22, no 2, pp. 147-162.

Del Rey Morato, J. (2007). Comunicación política, Internet y campañas electorales: de la Teledemocracia a la Ciberdemocracia. Madrid: Tecnos.

Deuze, M. (2012). Media Life. Cambridge: Polity Press.

Díaz Arias, R. (2015). Curaduría periodística, una forma de reconstruir el espacio público. Estudios sobre el Mensaje Periodístico. 2015, 21, pp. 61-80. 
Fernández, C. B. (2012). Twitter y la ciberpolítica. Anuario electrónico de estudios en Comunicación Social "Disertaciones", vol. 5, no 1, pp. 9-24.

Fernández, C. B. (2008). Ciberpolítica: ¿Cómo usamos las tecnologías digitales en la política latinoamericana? Buenos Aires: Konrad Adenauer Stiftung. Disponible en http://www.ciberpolitica.net.

Gainous, J. y Wagner, K. (2014). Tweeting to power: The social media revolution in American politics. Oxford: Oxford University Press.

Giansante, G. (2015). La comunicación política online. Barcelona: UOC.

Hendricks, J. y Kaid, L. (2010). (eds.). Technopolitics in presidential Campaigning. Nueva York: Routledge.

Holtz-Bacha, C. (2013). Web 2.0: nuevos desafíos en comunicación política. Bien Común. 220, pp. 60-69.

Humanes, M. L. (2014). Exposición selectiva y partidismo de las audiencias en España. El consumo de información política durante las campañas electorales de 2008 y 2011. Palabra Clave, 17 (3), pp. 773-802.

Iyengar, S. y McGrady, J. (2007). Media Politics: A Citizen's guide. New York: W.W. Norton.

Jenkins, H. y Thorburn, D. (eds.) (2003). Democracy and New Media. Cambridge: The M.I.T. Press.

Kelly, J. (2008). Pride of Place: Mainstream Media and the Networked Public Sphere. Media Re: Public. Side of Papers. Berkman Center for Internet and Society at Harvard University. Disponible en https://cyber.harvard.edu/sites/cyber.law.harvard.edu/files/Pride\%20of\%20 Place_MR.pdf

Key, Vo (1955). A theory of critical elections. The Journal of Politics, vol 17, no 1, pp. 3-18.

Lasorsa, D. L., Lewis, S. C. y Holton, A. E. (2012). Normalizing Twitter: Journalism practice in an emerging communication space. Journalism studies, vol. 13, no 1, pp. 19-36.

Lazarsfeld, P., Berelson, B. y Gaudet, H. (1948). The people's choice. Nueva York: Columbia University Press.

López-Meri, A. (2016). Twitter-retórica para captar votos en campaña electoral. El caso de las elecciones de Cataluña de 2015. Comunicación y Hombre, 12, pp. 97-118.

López-Meri, A. y Casero-Ripollés, A. (2016). El debate de la actualidad periodística española en Twitter: Del corporativismo de periodistas y políticos al activismo ciudadano. Observatorio $\left(O B S^{*}\right)$, vol. 10, no 3 .

Maarek, P. (2014). Politics 2.0: New Forms of Digital Political Marketing and Political Communication. Trípodos, 34, pp. 13-22.

Martin Algarra, M., Torregrosa, M. y Serrano-Puché, J. (2013). Un periodismo sin períodos: actualidad y tiempo en la era digital. En García, A. (Coord). Periodística y web 2.0: hacia la construcción de un nuevo modelo. Estudios de Periodística XVII. Madrid: CEU Ediciones, pp. 73-83.

Mazzoleni, G. (2001). La revolución simbólica de Internet. CIC: Cuadernos de información y comunicación, 6, pp. 33-38.

Mazzoleni, G. (2010). La comunicación política. Madrid: Alianza Editorial. 
Medina, M. (2015). La audiencia en la era digital. Madrid: Fragua.

Meilán, X. (2010). Causas y consecuencias del consumo de información política en España (20002009). Madrid: CIS.

Noguera Vivo, J. M. (2013). How open are journalists on Twitter? Trends towards the enduser journalism. Communication छ Society, vol. 26, no 1, pp. 93-114.

Orihuela, J. L. (2011). Mundo Twitter. Barcelona: Alienta.

Parmelee, J. y Bichard, S. (2012). Politics and the Twitter Revolution: How Tweets Influence the Relationship between Political Leaders and the Public. Lanham, MD: Lexington.

Rainie, L. y Wellman, B. (2012). Networked. The New Social Operating System. Cambridge, MA: The MIT Press.

Rodríguez Andrés, R. y Ureña, D. (2011). Diez razones para el uso de Twitter como herramienta en la comunicación política y electoral. Comunicación y pluralismo, 10, pp. 89-116.

Rodríguez-Virgili, J., López-Escobar, E. y Tolsá, A. (2011). La percepción pública de los políticos, los partidos y la política, y uso de medios de comunicación. Communication E̊ Society, vol. 24, no 2, pp.7-40.

Rodríguez-Virgili, J. y Fernández, C. B. (2017). Infopolítica en campañas críticas: el caso de Argentina, España y Venezuela en 2015. Comunicación y Hombre, no13. pp 85-102.

Serrano-Puché, J. (2017). Metaanálisis del consumo digital en el ecosistema mediático contemporáneo: factores distintivos e implicaciones emocionales. Revista Mediterránea de Comunicación, 8(1), pp. 75-85.

Stroud, N. J. (2010). Polarization and partisan selective exposure. Journal of Communication, 60 , pp. 556-576.

Stroud, N. J. (2011). Niche News: The Politics of News Choice: The Politics of News Choice. Oxford: Oxford University Press.

Strömback, J. (2008). Four phases of mediatization: An analysis of the mediatization of politics. The International Journal of Press/Politics, 13, no 3, pp. 228-246. 